\title{
Editorial
}

\section{HAPPY NEW YEAR!}

You will have already noticed the new look to the Journal of Laryngology and Otology. Times change and pressure from our advertisers has encouraged us to open up the inside covers for advertisements. In March we will be introducing an events column and also one for new products.

I am very pleased to welcome to the Editorial Team Mr Martin Bailey from The Royal National Throat, Nose and Ear Hospital and The Hospital for Sick Children, Great Ormond Street, Mr Liam Flood from Middlesbrough, and Mr Pat Bradley and $\mathrm{Mr}$ Nick Jones, both from Queens University Hospital, Nottingham.

Despite the increasing demands on your short reading time we hope you will continue to enjoy the ever varied contents of the Journal of Laryngology and Otology.

Neil Weir

Editor 
